\title{
Representação visual de sistemas: suporte para a construção colaborativa de sentidos na elaboração de jogos analógicos como projeto de pesquisa e aprendizagem no Ensino Médio
}

\author{
Visual representation of systems: support for the collaborative construction of \\ meanings in the elaboration of analog games as research and learning projects in \\ High School
}

\author{
Cynthia Macedo Dias \& Jackeline Lima Farbiarz
}

representação visual; design de jogos; jogos analógicos; colaboração

\begin{abstract}
Enquanto cresce a demanda por práticas pedagógicas que promovam a horizontalização das relações, a compreensão das partes no todo, o olhar sistêmico, a articulação teoria e prática, conhecimentos verbais e lineares permanecem no topo da hierarquia de saberes em relação ao pensamento visual e sistêmico. Apresentamos um recorte de uma experiência realizada em uma escola de Ensino Médio Integrado, estruturada em torno da criação coletiva de um jogo analógico a partir de um processo de pesquisa. A organização do processo foi inspirada no modelo de processo de projeto em Design denominado "duplo diamante". Após um momento expositivo e dialogado sobre a representação visual de sistemas, foram propostos três exercícios, progressivos em termos de complexidade do conteúdo, complexidade do formato de representação, configurações de colaboração e suportes. A representação visual serviu como diagnóstico, exercício, instrumento de apoio à aprendizagem e ao trabalho coletivo, e base para a definição das regras e do discurso do jogo criado a partir do sistema modelado. As dificuldades e avanços reforçam a importância da representação visual como suporte para o pensamento e o trabalho individual e colaborativo, e da mediação dos professores para o desenvolvimento de todos nas múltiplas inteligências envolvidas.
\end{abstract}

visual representation; game design; analog games; collaboration

\begin{abstract}
As grows the demand for pedagogical practices that promote the horizontalization of relationships, the understanding of the parts as a whole, the systemic view, the articulation of theory and practice, verbal and linear knowledge remain at the top of the hierarchy of knowledge in relation to visual and systemic thinking. We present an excerpt of an experience conducted in an Integrated High School, structured around the collective creation of an analog game based on a research process. The process organization was inspired by the design process model in Design named "Double Diamond". After an expository and dialogued moment about the visual representation of systems, three exercises were proposed, progressive in terms of content complexity, representation format complexity, collaboration configurations and supports. Visual representation served as a diagnosis, an exercise, a tool to support learning and collective work, and a basis for defining the rules and discourse of the game created from the modeled system. The difficulties and advances reinforce the importance of visual representation as support for individual and collaborative thinking and work, and of teachers' mediation for the development of all in the multiple intelligences involved.
\end{abstract}

\section{Introdução}

$\mathrm{Na}$ atualidade, demandam-se práticas pedagógicas que horizontalizem as relações entre alunos e professores; promovam a compreensão das partes no todo em um olhar sistêmico; estimulem a articulação teoria e prática, a atividade e problematização para promoção da autonomia e o trabalho colaborativo, especialmente no ensino integrado (Frigotto \& Araújo, 2015). Entretanto, no sistema educacional brasileiro, permanece a hierarquia do conhecimento verbal e linear em relação ao conhecimento visual e sistêmico.

Os jogos analógicos são um contexto de interesse dos estudantes e também sistemas

Anais do 9 CIDI e 9 CONGIC

Luciane Maria Fadel, Carla Spinillo, Anderson Horta,

Cristina Portugal (orgs.)

Sociedade Brasileira de Design da Informação - SBDI

Belo Horizonte | Brasil | 2019

ISBN $978-85-212-1728-2$
Proceedings of the 9th CIDI and 9th CONGIC

Luciane Maria Fadel, Carla Spinillo, Anderson Horta,

Cristina Portugal (orgs.)

Sociedade Brasileira de Design da Informação - SBDI

Belo Horizonte | Brazil | 2019

ISBN 978-85-212-1728-2 
Dias, C. \& Farbiarz, J. | Representação visual de sistemas: suporte para a construção colaborativa de sentidos na elaboração de jogos analógicos como projeto de pesquisa e aprendizagem no Ensino Médio

interativos de objetos em relação, que favorecem a visualização de informações e a compreensão de processos e do mundo como um sistema dinâmico de partes em interrelação e constante mudança (Zimmerman, 2013). Nos jogos analógicos, todos os elementos estão visíveis e são controlados pelos jogadores (Juul, 2005). O processo de criar um jogo analógico demanda a seleção, organização e representação visual de informações e a atuação colaborativa, contribuindo para o desenvolvimento de habilidades de pensamento visual e sistêmico, que ainda permanecem em posição subalterna em relação aos conhecimentos verbais e lineares.

A representação visual serve à elaboração de um jogo analógico especialmente quando se trata de um tema da realidade, na medida em que, nesses casos, como afirma Bogost (2008), o "sistema-fonte" não existe previamente, mas é definido durante o processo de seleção e definição do recorte pelos designers do jogo, a partir de sua subjetividade. Segundo ele, ainda, quando os jogadores interagem com a simulação construída, as '(...) lacunas entre o modelo procedimental elaborado pelo designer a partir de um sistema-fonte e a subjetividade do jogador, suas preconcepções e sua compreensão existente daquela simulação' (Bogost como citado por Fullerton, 2008, p. 57, tradução nossa) estimulam o jogador a cotejar seus próprios modelos de mundo com o modelo proposto pelo jogo. Esse processo, assim, demanda a construção de uma representação que auxilie na construção coletiva de conhecimentos dentro da equipe, bem como na tomada de decisões e no planejamento. A representação visual de um sistema como apoio à criação de um jogo analógico, assim, poderia servir como exercício para o pensamento visual e sistêmico na escola.

\section{Método}

Visando refletir na ação sobre o problema desta pesquisa, desenvolveu-se uma experiência junto a alunos do Ensino Médio integrado ao técnico de uma escola federal da zona Norte do Rio de Janeiro. A disciplina já tinha como foco a pesquisa sobre um tema relacionado à formação técnica e aos Eixos teóricos do currículo. O processo de criação coletiva de um jogo analógico estruturou o programa da disciplina e a pesquisa dos estudantes, referenciado no modelo de projeto "duplo diamante" (Design Council, 2007). Participaram 14 alunos e alunas, duas preceptoras ${ }^{1}$ e uma estagiária, em 14 encontros quinzenais ao longo de um ano. Uma das preceptoras é uma das autoras deste artigo.

A representação visual de sistemas foi trabalhada em um momento teórico (uma aula para introduzir diferentes formas de representação visual, como infográfico, mapa mental, entre outros e promover a compreensão da representação como síntese de um assunto complexo) e três momentos práticos: 1) um exercício em que os estudantes representaram em seus cadernos como funciona um sistema conhecido: o refeitório da escola; 2) um exercício em que, em duplas, produziram mapas mentais em cartolinas, a partir de pesquisa nos celulares sobre seus interesses, dentro do tema selecionado pela turma; 3 ) um exercício de representação coletiva de um sistema mais complexo, fruto da pesquisa da turma, como mapa conceitual reconfigurável. Esses momentos estão sintetizados na Tabela 1.

Tabela 1: momentos de aula que trabalharam representação visual

\begin{tabular}{l|l|l|l} 
Aula $\mathrm{n}^{\circ}$ & 4 de 14 & 6 de 14 & 10 de 14 \\
\hline Momento teórico & $\begin{array}{l}\text { Aula expositiva e } \\
\text { dialogada }\end{array}$ & - & - \\
\hline Momentos práticos & $\begin{array}{l}\text { Representação do } \\
\text { sistema do refeitório }\end{array}$ & $\begin{array}{l}\text { Representação da } \\
\text { pesquisa exploratória }\end{array}$ & $\begin{array}{l}\text { Representação do } \\
\text { sistema estudado }\end{array}$ \\
\hline
\end{tabular}

Para análise e discussão, foram utilizados como base o diário de uma das preceptoras e os trabalhos desenvolvidos pelos estudantes, focando nas potências, lacunas e aprendizados.

\footnotetext{
1 Nessa disciplina, os professores são chamados de preceptores, por sua função de orientação e mediação na pesquisa.
}

Anais do 9 Congresso Internacional de Design da Informação | CIDI 2019

Proceedings of the 9th Information Design International Conference

Anais do $9^{\circ}$ Congresso Nacional de Iniciação Científica em Design da Informação | CONGIC 2019

Proceedings of the $9^{\text {th }}$ Information Design Student Conference 
Dias, C. \& Farbiarz, J. | Representação visual de sistemas: suporte para a construção colaborativa de sentidos na elaboração de jogos analógicos como projeto de pesquisa e aprendizagem no Ensino Médio

\section{Resultados}

O pensamento sistêmico e visual foram trabalhados em etapas progressivas, considerando o conteúdo ou tema a ser representado; a complexidade da representação visual solicitada na atividade; o tamanho do grupo que estaria trabalhando em conjunto; e o suporte da representação. Essa progressão serviu para preparar o grupo para colaborar na construção da representação visual do sistema final, que seria base para construção do jogo pela turma. Ao mesmo tempo, referencia-se no processo de projeto estruturado no modelo de "duplo diamante" e no uso de ferramentas e técnicas de representação visual para desenvolvimento de projetos em Design (Pazmino, 2015).

Figura 1: Modelo de processo de Design Duplo Diamante (Design Council, 2007) adaptado para o contexto da criação de jogos analógicos com estudantes de Ensino Médio. Fonte: as autoras

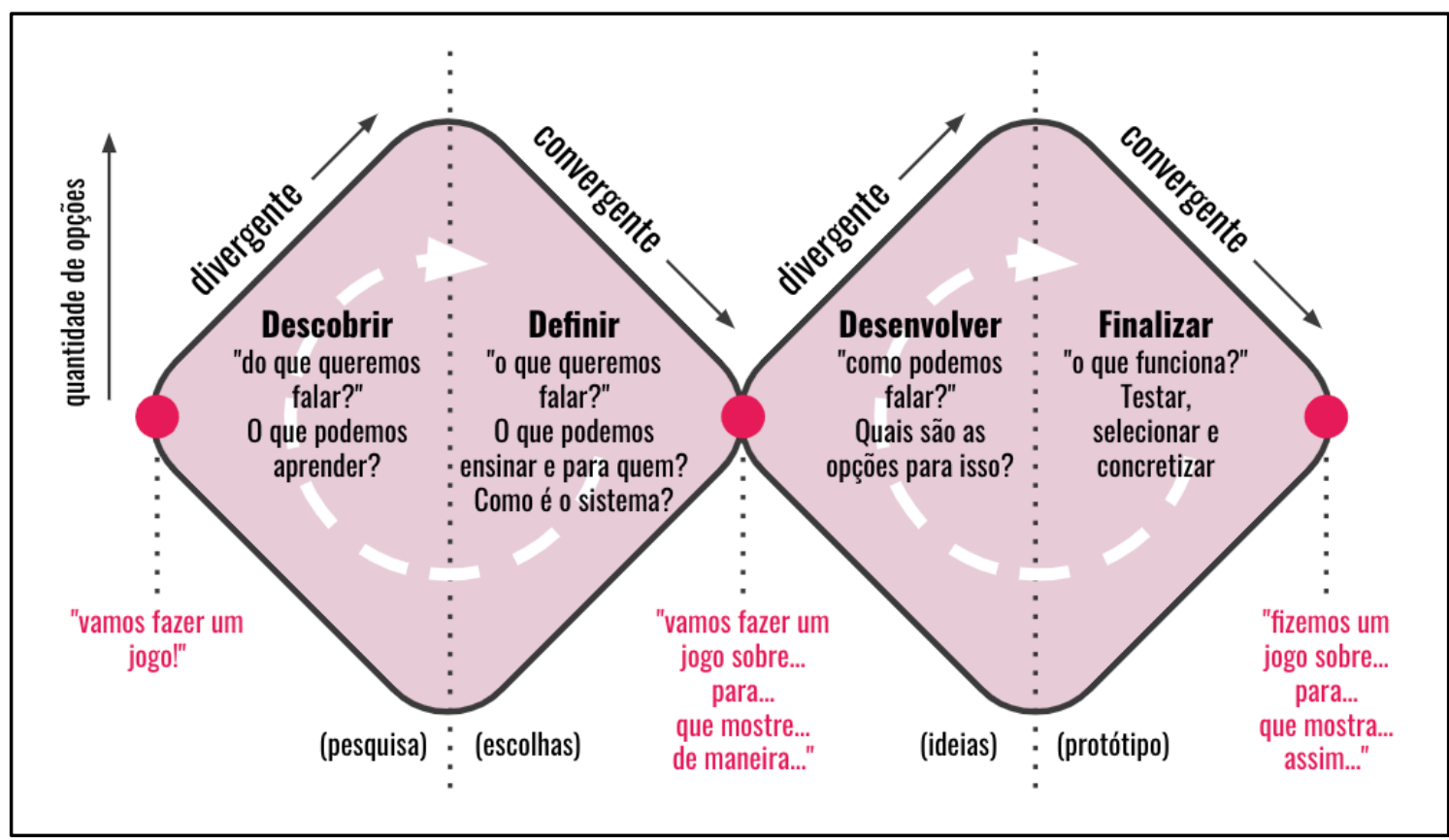

As etapas referentes à representação visual de sistemas e suas características estão resumidas na Tabela 2.

Tabela 2: características das atividades desenvolvidas

\begin{tabular}{l|l|l|l} 
& $\begin{array}{l}\text { 1) Representação do } \\
\text { sistema do refeitório }\end{array}$ & $\begin{array}{l}\text { 2) Representação da } \\
\text { pesquisa exploratória }\end{array}$ & $\begin{array}{l}\text { 3) Representação do } \\
\text { sistema estudado }\end{array}$ \\
\hline $\begin{array}{l}\text { Fase do processo } \\
\text { (duplo diamante) }\end{array}$ & Contexto & Divergente (pesquisa) & Convergente (escolhas) \\
\hline Conteúdo & sistema conhecido & $\begin{array}{l}\text { tema inicial de pesquisa } \\
\text { exploratória }\end{array}$ & tema da pesquisa final \\
\hline Complexidade & representação livre & $\begin{array}{l}\text { mapa mental com } \\
\text { elementos específicos }\end{array}$ & $\begin{array}{l}\text { mapa conceitual } \\
\text { orientado }\end{array}$ \\
\hline Participação & $\begin{array}{l}\text { individual com diálogo } \\
\text { em duplas ou trios }\end{array}$ & duplas & $\begin{array}{l}\text { grupo (mediado pelas } \\
\text { preceptoras) }\end{array}$ \\
\hline Suporte & caderno & cartolina & mesa com post-its \\
\hline
\end{tabular}

Assim, passamos por: 1) conteúdo - de um sistema conhecido (o refeitório da escola) para um tema inicial de pesquisa exploratória, para o tema da pesquisa final; 2) complexidade visual - de uma proposta livre para uma proposta de mapa mental incluindo elementos específicos, para uma proposta de mapa conceitual com elementos e características visuais específicos (Pazmino, 2015); 3) participação - de um exercício individual com diálogo em duplas ou trios para um exercício em duplas, para um exercício de todo o grupo coletivamente, mediado pelas

Anais do 9 Congresso Internacional de Design da Informação । CIDI 2019

Proceedings of the 9th Information Design International Conference

Anais do $9^{\circ}$ Congresso Nacional de Iniciação Científica em Design da Informação | CONGIC 2019

Proceedings of the $9^{\text {th }}$ Information Design Student Conference 
Dias, C. \& Farbiarz, J. | Representação visual de sistemas: suporte para a construção colaborativa de sentidos na elaboração de jogos analógicos como projeto de pesquisa e aprendizagem no Ensino Médio

preceptoras; 4) suporte - do caderno para cartolinas e finalmente para a mesa, com uso de post-its e palitos para compor os elementos do mapa.

$\mathrm{Na}$ parte teórica da aula, discutimos sobre sistemas como conjuntos de partes que se relacionam para formar um todo, e formas de representação visual, como infográficos, mapas mentais, além de vídeos com animações que explicam sistemas, como a Série SUS (Floss e Prado, 2015). Alguns dos exemplos exibidos na aula estão nas Figuras 2 e 3.

Figura 2: Exemplo de infográfico

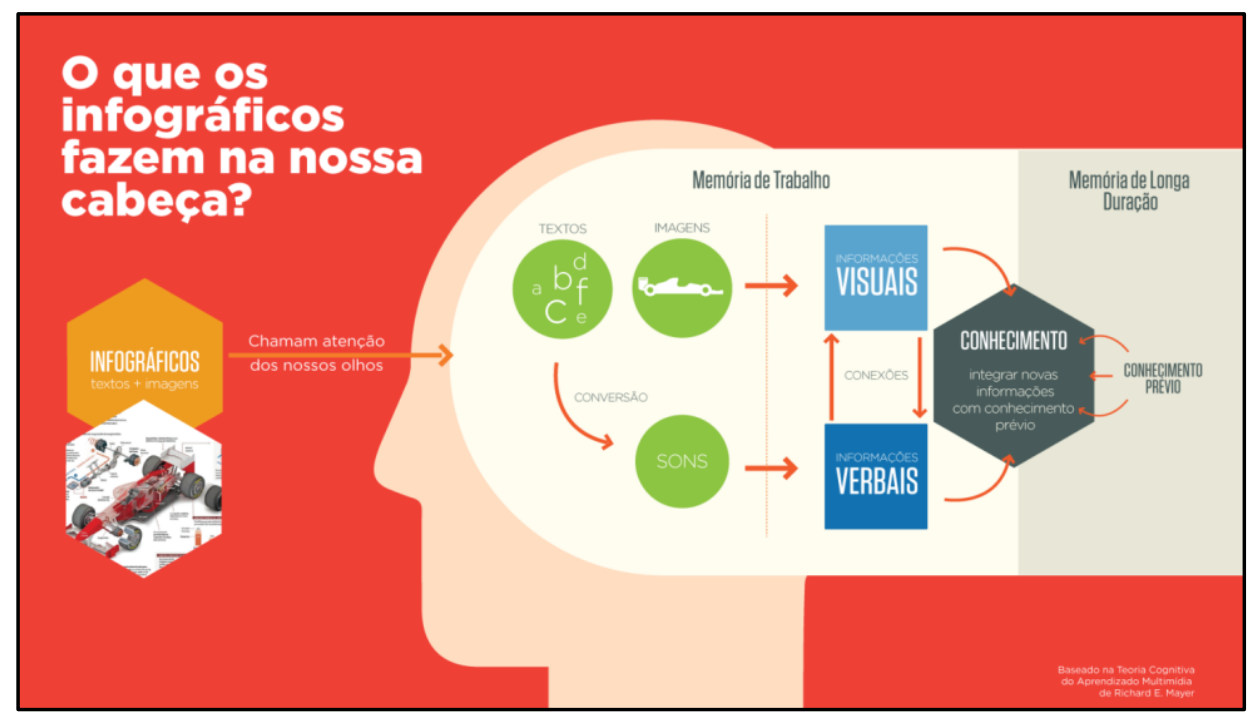

Figura 3: Exemplo de mapa mental

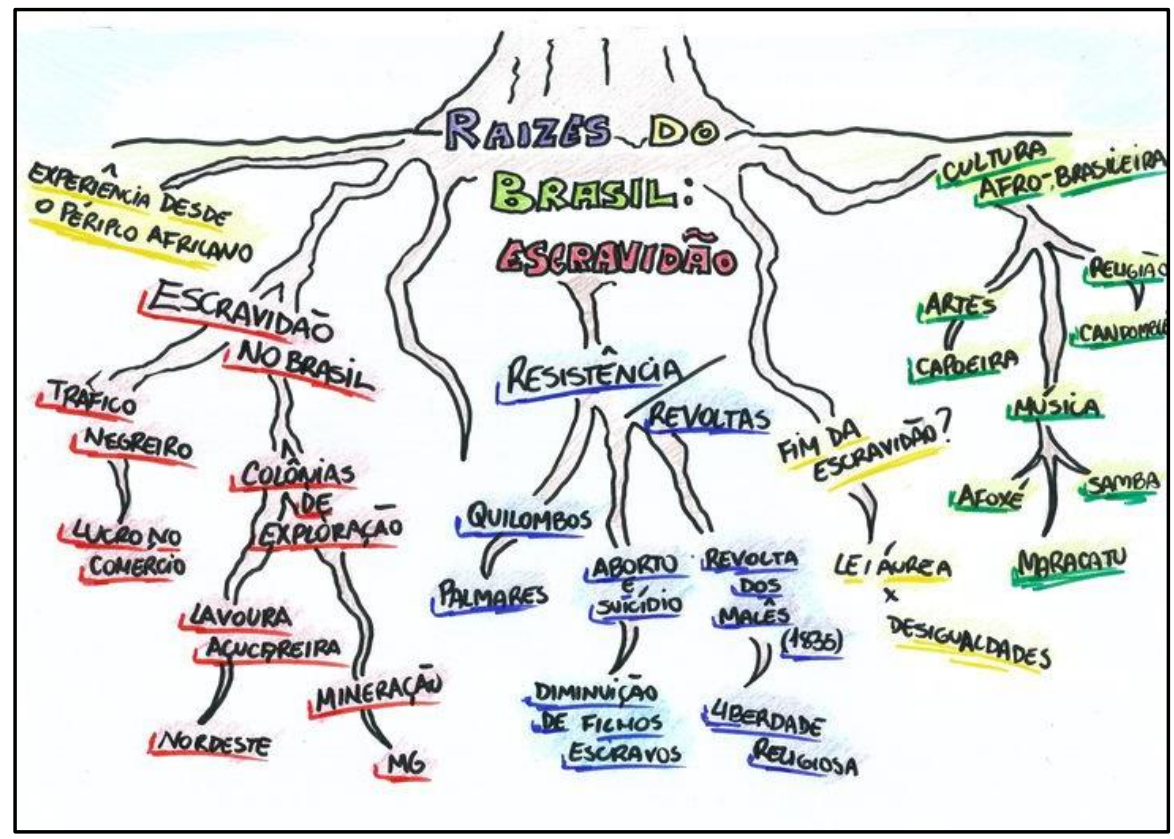

O primeiro exercício tinha como objetivo propiciar aos estudantes a experimentação da representação visual, bem como levantar estilos de representação e formas de organização da informação utilizados por eles. Por isso, a atividade foi livre, não indicando nenhum formato de representação a ser buscado. Propor a representação do refeitório nos cadernos como primeira atividade se mostrou uma escolha acertada, por ser um "sistema" conhecido, que faz parte do cotidiano dos estudantes. Este demonstrou ser relativamente simples de ser representado em um tempo curto, fazendo com que os estudantes expressassem menos dificuldades e mais 
Dias, C. \& Farbiarz, J.| Representação visual de sistemas: suporte para a construção colaborativa de sentidos na elaboração de jogos analógicos como projeto de pesquisa e aprendizagem no Ensino Médio

autonomia e pudessem passar em seguida, na mesma aula, para a criação de um jogo simples a partir do sistema representado. A divisão em quatro duplas ou trios, com a realização individual nos cadernos, também favoreceu o diálogo e colaboração entre os estudantes ao mesmo tempo que sua expressão individual.

Ao propor a atividade, chegamos a comentar a possibilidade de se pensar o sistema do refeitório de forma expandida, incluindo a participação de profissionais, as formas de abastecimento, entre outros componentes. Porém, naturalmente, a maior parte dos estudantes representou o que era mais próximo de sua própria relação com o sistema: o funcionamento do atendimento no refeitório, materializado na fila, que tem uma entrada, pessoas que passam por ela, ações que acontecem no intermédio (incluindo colaborações e conflitos) e uma saída, como um sistema linear.

Seguindo essa lógica, dois dos quatro grupos representaram uma espécie de "planta baixa" da área do refeitório, vista de cima, com o fluxo de pessoas representado com o auxílio de setas. No terceiro grupo, os estudantes fizeram uma representação esquemática ilustrada com desenhos, mostrando as etapas de preparação e atendimento conectadas por setas, como um infográfico. Os alunos do quarto grupo utilizaram o formato de mapa mental, com elementos conectados por linhas. No debate, surgiram comparações da "qualidade" dos desenhos mais figurativos em relação aos mapas mais gráficos, mas buscamos ressaltar que um certo padrão de desenho não é pré-requisito para comunicar sentidos visualmente e motivando que estes reconhecessem, nos próprios exemplos da turma, alguns dos muitos caminhos possíveis e eficazes para representar um sistema.

A representação visual que delineava o espaço físico do refeitório e um fluxo linear de ações realizadas nesse espaço foi tão pregnante na turma, que, ao serem solicitados a se dividirem novamente, agora em dois grupos maiores, para produzirem rapidamente jogos simples sobre o refeitório, a partir das representações produzidas, os dois grupos utilizaram a estrutura de jogos de "trilha" para representar a fila do refeitório. Esse formato, de fato, foi bem pertinente ao fluxo de ações que se dá no cotidiano dos estudantes. A partir de problematizações das preceptoras, eles incluíram nos jogos não apenas as ações realizadas em um sistema "ideal", mas também tensões e conflitos. Entretanto, as regras dos jogos continham ainda poucos recursos conceituais, de uso da retórica procedimental (Bogost, 2010), ou seja, de que a estrutura das regras "dissesse" algo sobre o tema. Sendo jogos de trilha, estes eram baseados prioritariamente na sorte, na rolagem de dados, para verificar o quanto os estudantes "andariam" na fila e o que aconteceria com eles, dependendo da casa em que caíssem no tabuleiro.

Percebemos, assim, que seria interessante trabalhar mais a fundo a representação visual de maneira mais abstrata e conceitual, a fim de que os estudantes exercitassem a compreensão e a representação de relações conceituais, que demandam reflexões mais profundas e a percepção de sistemas como conjuntos de objetos em relação, relações estas que podem ser explícitas ou implícitas, "regras" visíveis ou invisíveis, e não apenas mecânicas, mas de influências, relações mais complexas em que a causalidade nem sempre é linear e determinística.

Na segunda atividade, as preceptoras propuseram uma atividade de pesquisa em dupla sobre os temas que eles mais se interessassem, dentro dos temas levantados coletivamente na aula anterior. A partir da pesquisa, realizada nos próprios celulares dos estudantes, estes deveriam produzir mapas mentais com a representação visual dos achados.

Pazmino (2015) relata que o mapa mental foi desenvolvido pelo psicólogo Tony Buzan na década de 1970 e, segundo o modelo criado por ele, deveria ser configurado preferencialmente colocando o tema no centro de uma folha grande, utilizada na horizontal, com linhas curvas saindo do tema central para todos os lados, abrindo categorias associadas a ele, e utilizando cores, símbolos, figuras.

Além de exercitar a produção de mapas mentais, essa atividade serviu ainda como etapa de exploração de temas, dentro do momento de "abertura" no processo "duplo diamante" (Design Council, 2007). Foi solicitado, ainda, que buscassem identificar e apontar, nos mapas, elementos de sistemas, como personagens, ambientes e suas relações, se havia conflito ou cooperação, regras visíveis ou invisíveis, para tentarmos, com isso, buscar possíveis caminhos 
Dias, C. \& Farbiarz, J. | Representação visual de sistemas: suporte para a construção colaborativa de sentidos na elaboração de jogos analógicos como projeto de pesquisa e aprendizagem no Ensino Médio

de elaboração do jogo da turma, do que gostaríamos de "dizer" com nosso jogo. Ao longo do processo, fomos mediando a pesquisa e esclarecendo dúvidas.

Todos os cartazes foram produzidos pelos estudantes à mão livre, com canetas e/ou lápis sobre cartolinas. Para fins deste artigo, reconstruímos os cartazes utilizando a ferramenta Google Drawings, de maneira a facilitar a leitura dos elementos inseridos e dificultar a identificação dos trabalhos. Foram mantidas as proporções dos elementos, os recursos gráficos (linhas, setas e formas) e as cores utilizadas pelos alunos. A cor cinza foi usada para representar a escrita a lápis. Quando foram necessários pequenos ajustes, estes são indicados no texto.

O cartaz da Figura 4 coloca o tema central como título, conectado por linhas às suas partes, indicando a relação direta das três formas de acesso à saúde com o tema. Apresenta em seguida uma caracterização do tema, subdividido nas categorias existentes. Para cada categoria, apesar de não nomeados, é possível identificar os elementos solicitados:

- ambientes (tipos de unidades de saúde presentes em cada sistema);

- personagens (classes sociais atendidas em cada sistema);

- conflitos (limitações de cada sistema).

Figura 4: Cartaz produzido por estudantes com tema "Saúde antes do SUS"

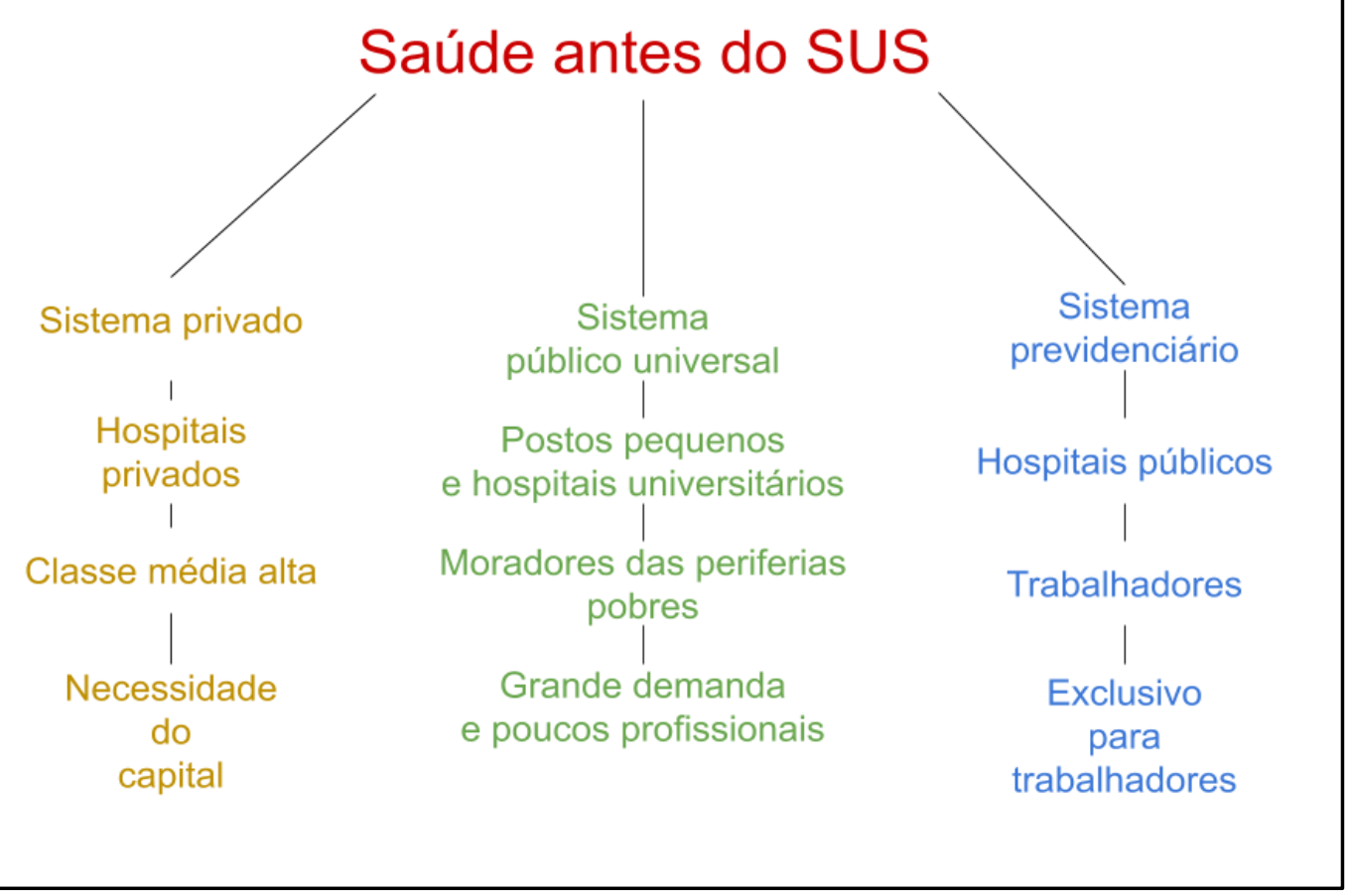

Apresenta um paralelismo na apresentação das informações, o que facilita a comparação entre os sistemas, e aponta conflitos ou desafios, elementos que têm um potencial para serem explorados na elaboração de jogos.

O tema central do cartaz da Figura 5 é bem definido, mas tratado como "título", desconectado graficamente do conteúdo. Subdivide o tema nos países que os estudantes selecionaram, apontando uma característica principal da forma de atendimento para HIV-AIDS em cada um. Entretanto, as características elencadas são pontuais e resumem muita informação em poucos elementos visuais, dificultando o paralelismo e a visualização de relações, conflitos, regras visíveis e invisíveis. 
Dias, C. \& Farbiarz, J. | Representação visual de sistemas: suporte para a construção colaborativa de sentidos na elaboração de jogos analógicos como projeto de pesquisa e aprendizagem no Ensino Médio

Figura 5: Cartaz produzido por estudantes com tema "Tratamento para HIV-AIDS em diferentes países"

\section{Tratamento para HIV-AIDS em diferentes países}

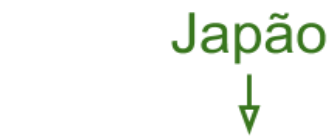

Hospitais específicos para o tratamento e equipes especializadas (PEP)

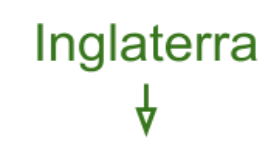

Tratamento através de medicação profilática pós-exposição

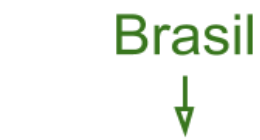

Soropositivos recebem medicamentos antirretrovirais pela rede pública

Os conflitos ou desafios não estão claros, mas poderiam ser trabalhados ou explorados em etapas posteriores da pesquisa. Percebemos a coleta e síntese de informações, mas apresenta-se uma oportunidade de trabalhar a transformação de informações no sentido da decupagem, de encontrar elementos e buscar representar as relações entre estes, movimento frutífero para a idealização de regras de jogo.

O cartaz da Figura 6 traz um tema central complexo e em forma de pergunta, que sugere uma experiência: uma situação e uma consequência, uma necessidade de ação e um caminho a se tomar. O mapa, entretanto, não indica esses caminhos ou relações entre os elementos do "sistema" pesquisado. As conexões (setas) apenas orientam a leitura (linear) do cartaz. Se as categorias (personagens, ambientes, conflitos) tivessem sido conectadas diretamente ao tema central e abertas novas linhas para os subitens, o mapa estaria mais parecido com a proposta de mapa mental. Entretanto, os tipos de informação solicitados estão presentes e são utilizados como categorias para elaborar subdivisões gráficas e organizar os elementos:

- personagens - "paciente doente; profissionais" (potencial para diferenciação de papeis de jogadores);

- ambientes - "unidades de saúde dos países", sem caracterização de que unidades seriam;

- conflitos - apresenta limitações de cada sistema. 
Dias, C. \& Farbiarz, J.| Representação visual de sistemas: suporte para a construção colaborativa de sentidos na elaboração de jogos analógicos como projeto de pesquisa e aprendizagem no Ensino Médio

Figura 6: Cartaz produzido por estudantes com tema "Se você pegar uma doença, o que você fará dependendo do país?"

\section{tema:}

Se você pegar uma doença o que você fará dependendo do país?

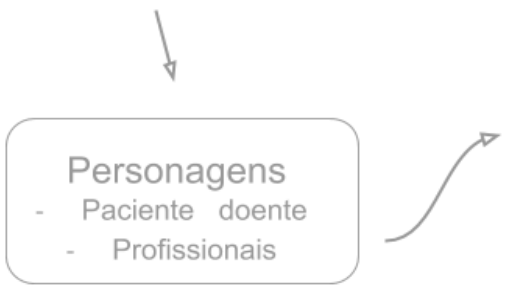

\section{Conflitos:}

- Taiwan - cidadãos estrangeiros não têm acesso.

- Suíça - seguro de saúde muito alto.

- Brasil - hospitais precários e falta de atendimento

- EUA - A maior parte é privatizada

- Venezuela - sem materiais necessários.

个

Ambientes:

Unidades de Saúde dos Países

- Taiwan

- Suíça

- Brasil

- EUA

- Venezuela

As características que ajudariam a diferenciar cada sistema estão concentradas nos conflitos, enquanto seus personagens e ambientes seriam análogos. Os conflitos ou desafios dos sistemas não apresentam paralelismo, tratam de questões diferentes, mas trazem potencial para elaboração de jogos, a partir de pesquisa mais aprofundada.

Figura 7: Cartaz produzido por estudantes com tema "Defeitos do SUS"

\section{Defeitos do SUS}

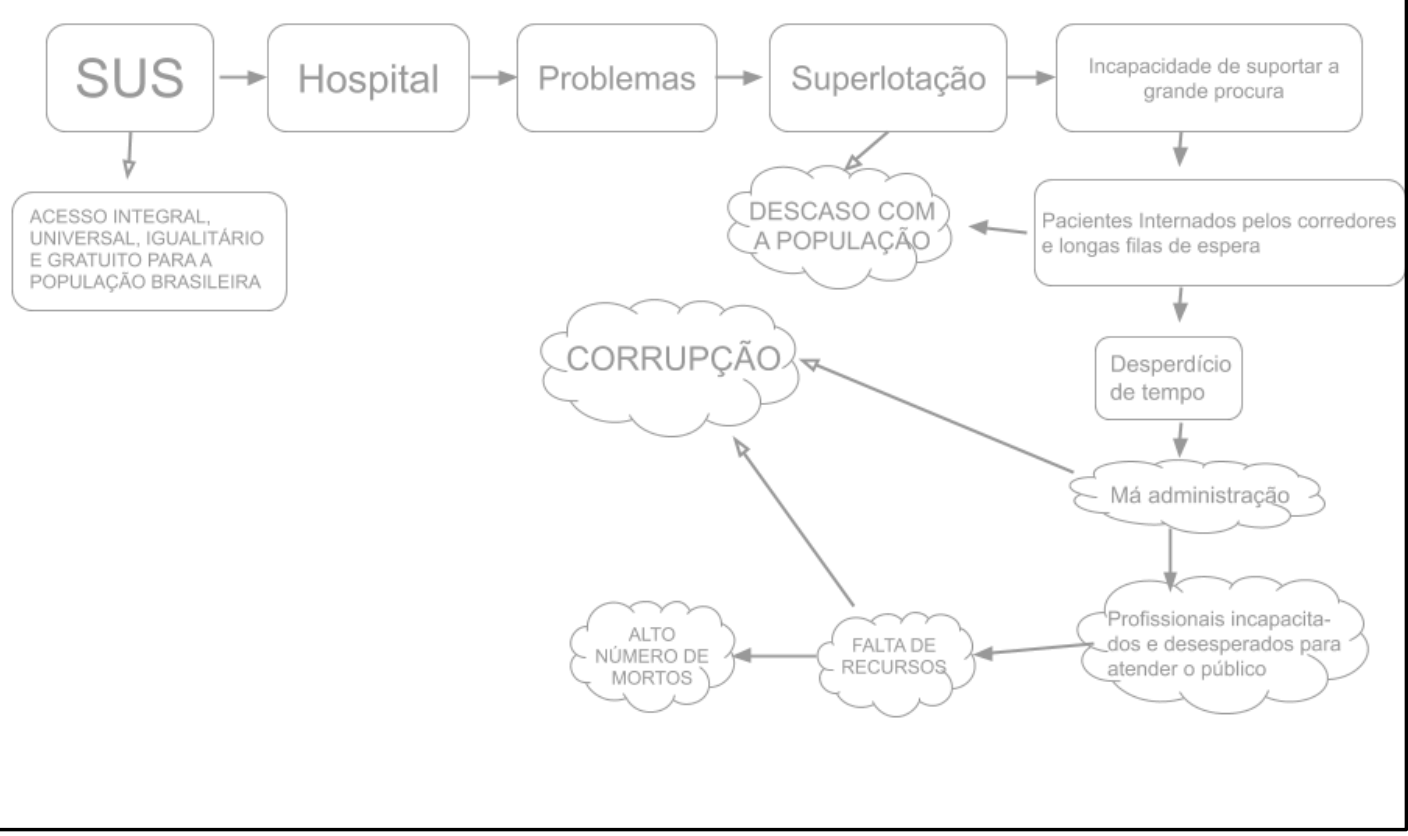


Dias, C. \& Farbiarz, J. | Representação visual de sistemas: suporte para a construção colaborativa de sentidos na elaboração de jogos analógicos como projeto de pesquisa e aprendizagem no Ensino Médio

O tema central desse cartaz (Figura 7) é complexo e contém um posicionamento bem claro a respeito do sistema de saúde: de que é um sistema com defeitos. O tema foi colocado como título, sem conexão gráfica com o conteúdo. Apresenta uma organização prioritariamente linear, criando uma associação de ideias que parte do SUS como primeiro elemento e constrói uma progressão de informações associadas, com algumas ramificações e interconexões que sugerem associações também lineares. O caminho termina com a "corrupção" no centro, relacionada à falta de recursos e à má administração. Traz muitos conflitos ou desafios com potencial para elaboração de jogos, mas pouca elaboração significativa das relações entre os elementos elencados, além de não trabalhar claramente os elementos solicitados. Por vezes as conexões apontam uma causa, outras vezes uma consequência, outras vezes simplesmente uma relação que não apresenta uma valoração clara.

Figura 8: Cartaz produzido por estudantes com tema "Defeitos do SUS"

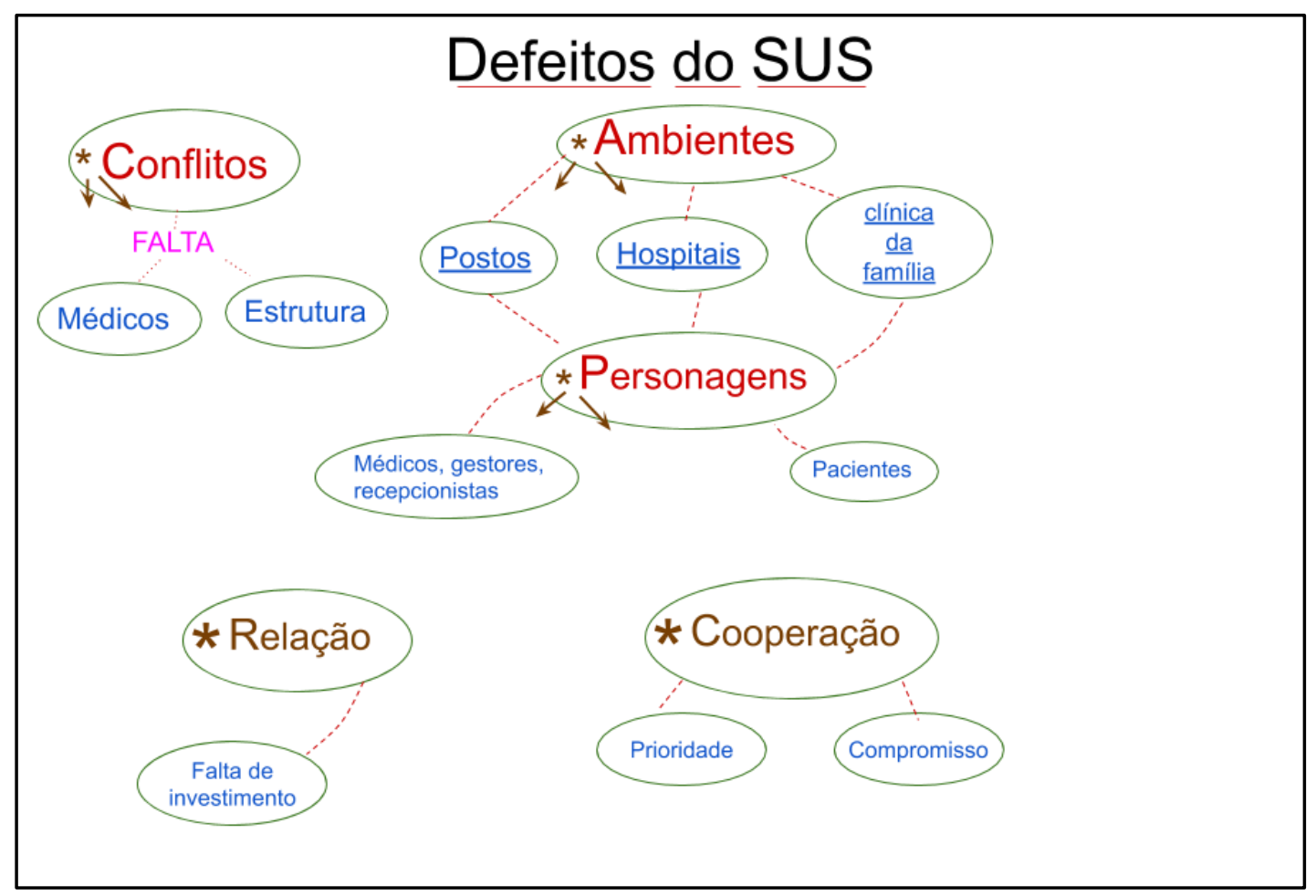

O cartaz da Figura 8 traz o mesmo tema central do cartaz da Figura 6: complexo e posicionado claramente em relação ao sistema de saúde como um sistema com defeitos. $\mathrm{O}$ tema também é colocado como título, sem conexão gráfica com o conteúdo. Nesse caso, apresenta os elementos propostos e constrói uma organização não-linear das informações, embora pudessem estar um pouco mais estruturadas, dentro da proposta de um mapa mental.

- ambientes - postos, hospitais e clínica da família (diferencia categorias - a noção de "ambientes" ajudou a compreender a pluralidade);

- personagens (conecta com ambientes, pois circulam neles) - médicos, gestores, recepcionistas e pacientes (diferencia papeis);

- conflitos - "médicos" e "estrutura" (apontados como aquilo que falta);

- cooperação - "prioridade" e "compromisso";

- relação - "falta de investimento" (compreensão da "relação" como um sentido encontrado a partir do que construíram no mapa, e não necessariamente como a próprio ato de se construir o mapa e colocar os objetos em relação).

Incluir os elementos solicitados aparentemente ajudou a construir uma visão mais ampla e complexa da situação, mas esse cartaz representou as relações de forma diferente do que seria esperado para um mapa mental. A "relação" foi destacada como uma categoria, como 
Dias, C. \& Farbiarz, J. | Representação visual de sistemas: suporte para a construção colaborativa de sentidos na elaboração de jogos analógicos como projeto de pesquisa e aprendizagem no Ensino Médio

algo externo, indicada pelos asteriscos que associam elementos do mapa. Incluir conflito e cooperação traz muito potencial para um jogo.

Na produção de mapas mentais em dupla, percebemos que não ficou claro, para todos os estudantes, o sentido de elencar personagens, ambientes e suas relações, tanto pelas dúvidas apresentadas durante a aula, quanto pelo fato de que esses elementos e sua organização nãolinear não estiveram visíveis em todos os cartazes. Verificamos uma tendência, em alguns grupos, a utilizar as cartolinas como suportes de apresentação, e não como suportes para pensar, questionando achados e escolhas e reconfigurando o mapa conforme o avanço da pesquisa. O tempo dedicado a esse exercício também foi limitado ao tempo de uma aula, na qual os estudantes não apenas pesquisaram mas também produziram os mapas.

Com esse exercício, percebemos a variedade de abordagens utilizadas pelos estudantes e a necessidade de trabalhar mais diretamente o uso da representação visual esquemática como estratégia de pesquisa e pensamento colaborativo, além da transformação das informações obtidas em relações entre elementos. Os cartazes serviram como base para uma discussão coletiva a respeito dos temas pesquisados pelos estudantes, além da problematização de desdobramentos que poderiam surgir de cada tema, e elementos que poderiam complementar aqueles representados. Além disso, serviram para ajudar os estudantes a votar nos temas de maior interesse, após a pesquisa realizada.

O tema escolhido pela turma, após problematização acerca dos "defeitos do SUS", foi como funciona o Sistema de Regulação - SISREG -, que é utilizado para organizar as vagas no SUS. A fim de conhecer mais sobre esse tema, foi realizada uma entrevista com profissionais da área, que tomou toda uma aula, porém na qual poucos alunos puderam estar presentes. Após essa entrevista, propusemos a criação coletiva de um mapa conceitual, mediado pelas preceptoras. O mapa conceitual é semelhante ao mapa mental, mas traz a proposta de utilizar um conceito, palavras de enlace e preposições e funcionar como uma estratégia de aprendizagem e, no campo do Design, como uma forma de organizar o pensamento (Pazmino, 2015). As palavras de enlace e preposições poderiam facilitar a representação de relações entre as informações, que pudessem ser utilizadas posteriormente como recurso para a construção de regras do jogo.

Figura 9: Mapa conceitual produzido por estudantes e preceptoras sobre a atribuição de vagas no SISREG.

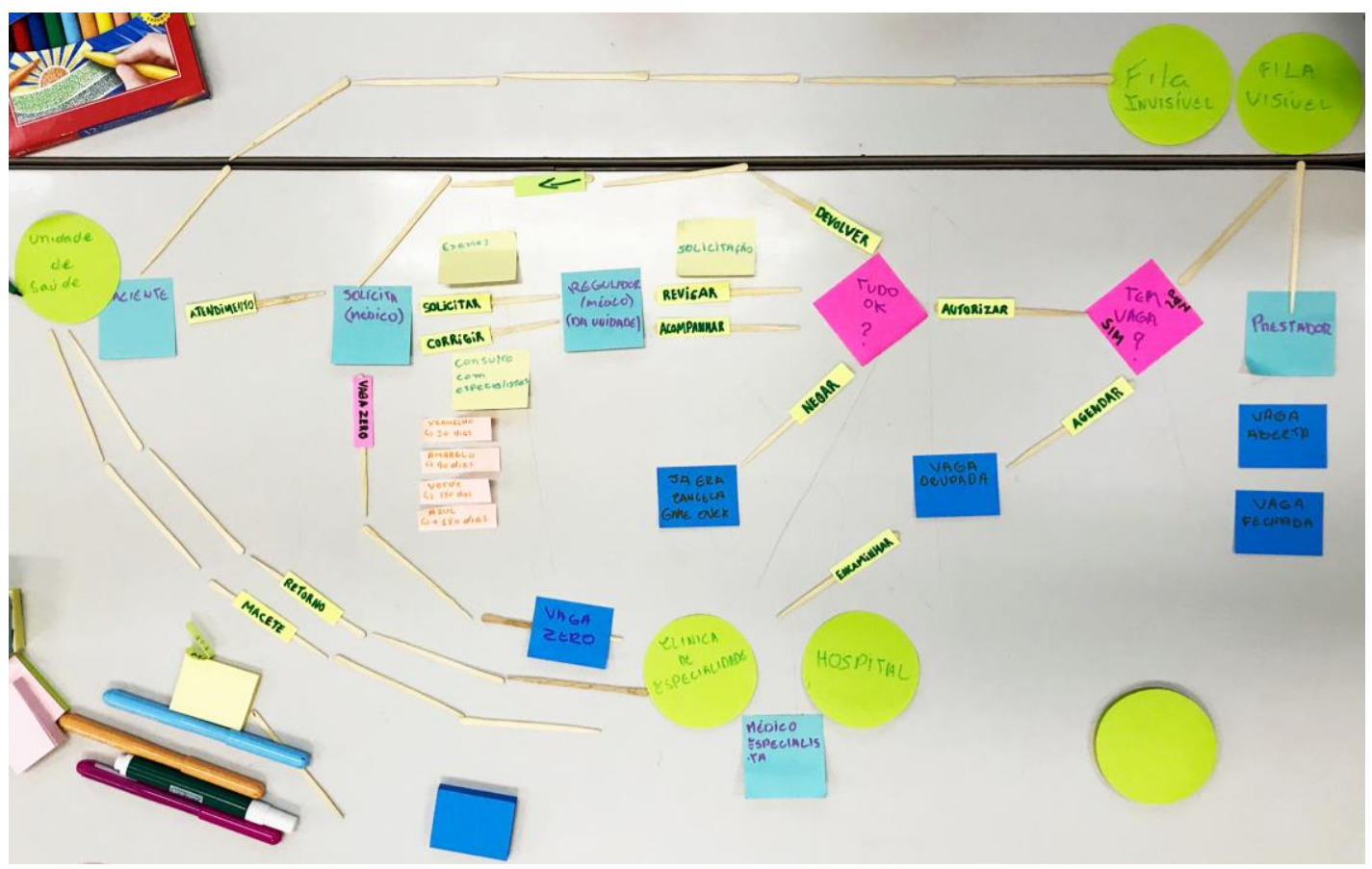

A fim de fomentar a participação coletiva e a reconfiguração do mapa conforme os sentidos fossem sendo esclarecidos, decidimos usar como suporte para o mapa uma mesa ampla e, para que este fosse reconfigurável, disponibilizamos post-its de diferentes cores e tamanhos

Anais do 9 Congresso Internacional de Design da Informação | CIDI 2019

Proceedings of the 9th Information Design International Conference

Anais do $9^{\circ}$ Congresso Nacional de Iniciação Científica em Design da Informação | CONGIC 2019

Proceedings of the $9^{\text {th }}$ Information Design Student Conference 
Dias, C. \& Farbiarz, J.| Representação visual de sistemas: suporte para a construção colaborativa de sentidos na elaboração de jogos analógicos como projeto de pesquisa e aprendizagem no Ensino Médio

para os elementos e palitos de madeira para as "conexões". A partir de diálogo no grupo e com mediação das preceptoras, foi atribuído um formato e cor diferente para cada categoria de informação, o que favoreceu a apropriação dos estudantes da configuração e reconfiguração do mapa. Os estudantes que estavam presentes na entrevista foram trazendo seus achados e compartilhando com o grupo, e fomos dialogando, problematizando e definindo coletivamente os elementos e suas relações. O mapa foi fotografado e impresso para embasar a seleção dos elementos e sentidos que comporiam o jogo e a elaboração das mecânicas que os representariam (Bogost, 2010).

A partir da análise do processo vivenciado e dos resultados dos exercícios, foi possível perceber, por um lado, a diversidade de formas de representação apresentadas pelos estudantes e sua apropriação das propostas, mas, por outro lado, uma inconsistência quando se trata de utilizar a linguagem visual de maneira significativa, e uma dificuldade de representar relações, especialmente ao abordar um tema ainda não "mapeado" em profundidade como um sistema. Visualizar um "sistema" a partir de um tema de pesquisa é um desafio complexo em si, que é exacerbado em decorrência da valorização, no ensino tradicional, de informações factuais, verbais e lineares, e de seu foco na recuperação de informações pontuais, em detrimento das relações entre os elementos que compõem os diversos sistemas de que participamos e do pensamento e da comunicação visuais. Essa dificuldade ficou patente na experiência realizada. Ao mesmo tempo, a representação visual de informações e sistemas na sala de aula permitiu enxergar diferentes olhares, com diferentes ênfases, para um mesmo fenômeno; provocar a descoberta de relações, hierarquias e causalidades; e comunicar visualmente essas informações e relações para viabilizar a reflexão e o trabalho coletivos, incluindo a elaboração das mecânicas do jogo criado pelo grupo.

\section{Conclusões}

As cobranças do ensino tradicional concentram-se, muitas vezes, na recuperação de informações, e não na reflexão sobre as relações entre objetos que compõem os diversos sistemas de que participamos. A representação visual de informações na sala de aula permitiu aplicar diferentes olhares, com diferentes ênfases, para um mesmo fenômeno (no caso do refeitório); destacar interesses e fazer emergir relações (no caso dos cartazes sobre a pesquisa) e elaborar coletivamente e de forma iterativa sentidos sobre um sistema que estava sendo conhecido pelo grupo (no sistema final). A multiplicidade de formas de representação apresentadas pelos estudantes mostra a riqueza de propor esse tipo de trabalho na escola, tanto como diagnóstico quanto como exercício de produzir e reconhecer diferentes formas de representação visual e sistêmica de informações.

Com múltiplas possibilidades de pesquisa postas, as representações visuais apoiaram a abertura e fechamento no processo de design do jogo analógico, nosso objetivo "material" final, e o processo de pesquisa e criação colaborativa, nosso objetivo pedagógico. Os diferentes modelos utilizados pelos estudantes oportunizaram a reflexão sobre múltiplos caminhos para a construção de sentidos a partir da representação visual de sistemas. O sistema representado no mapa coletivo favoreceu o compartilhamento e a aprendizagem das relações entre os elementos e, com isso, a construção coletiva de mecânicas coerentes com os sentidos que se desejava comunicar.

As dificuldades encontradas inicialmente e o avanço no trabalho reforçam a importância de se trabalhar a representação visual como suporte para o pensamento e o trabalho individual $e$ colaborativo, e da mediação dos professores para o desenvolvimento de todos, em suas especificidades. Finalmente, para fomentar o processo de construção colaborativa de sentidos a partir da representação visual de sistemas, é essencial que a formação de professores incorpore modos de fomento ao trabalho colaborativo, com linguagens, gêneros discursivos e multimodalidade, assim valorizando e desenvolvendo diferentes inteligências, como a interpessoal, intrapessoal, lógica-sistêmica e visual, como propostas por Gardner (1995). 
Dias, C. \& Farbiarz, J. | Representação visual de sistemas: suporte para a construção colaborativa de sentidos na elaboração de jogos analógicos como projeto de pesquisa e aprendizagem no Ensino Médio

\section{Agradecimento}

À contribuição dos pesquisadores do LINC - Laboratório Linguagem, Interação \& Construção de sentidos, da PUC-Rio, aos alunos, à preceptora e à estagiária participantes da experiência. O presente trabalho foi realizado com apoio da Coordenação de Aperfeiçoamento de Pessoal de Nível Superior - Brasil (CAPES) - Código de Financiamento 001.

\section{Referências}

Bogost, I. (2010). Persuasive Games: The Expressive Power of Videogames. Cambridge, MA: MIT Press, 2010.

Design Council. (2007). Eleven lessons: managing design in eleven global companies - Desk research report. London: Design Council. Disponível em www.designcouncil.org.uk

Floss, M., \& Prado, E. V. do. (2015). Os princípios do SUS. (07m52s) Disponível em: https://www.youtube.com/watch?v=PzVxQkNyqLs\&list=PL6uDN8MQ_oRCiqP6mvHRD 7EJJjS9T1bQk\&index=3. Acesso em 21 jul 2019.

Frigotto, G., \& Araujo, R. M. L. (2015). Práticas Pedagógicas e ensino integrado. Revista Educação em Questão (UFRN. Impresso), v. 52, pp. 61-80.

Gardner, H. (1995). Inteligências Múltiplas: A Teoria na Prática. Porto Alegre: Artes Médicas.

Juul, J. (2005). Half-Real: Video Games between Real Rules and Fictional Worlds. Kindle ed. Cambridge, MA; London, England: The MIT Press.

Fullerton, T. (2008). Game design workshop: a playcentric approach to creating innovative games. 2nd. ed. Elsevier: Massachussets.

Pazmino, A. V. (2015). Como se cria: 40 métodos para design de produtos. São Paulo: Edgard Blucher.

Zimmerman, E. (2013). Gaming literacy: Game design as a model for literacy in the twenty-first century. Intersemiose - revista digital, v. 4, pp. 23-31.

\section{Sobre as autoras}

Cynthia Macedo Dias, Msc, Escola Politécnica de Saúde Joaquim Venâncio, Fundação Oswaldo Cruz (Fiocruz), Brasil <cymadi@gmail.com>

Jackeline Lima Farbiarz, PhD, Pontifícia Universidade Católica do Rio de Janeiro - PUC-Rio

Brasil <jackeline@puc-rio.br> 